\title{
Tsafon
}

Revue d'études juives du Nord

$77 \mid 2019$

Contribution à l'histoire des traductions juives de la Bible hébraïque

\section{Chahut lors d'un colloque sur la Shoah en Pologne}

Par Danielle Delmaire

\section{(2) OpenEdition \\ Journals}

Édition électronique

URL : https://journals.openedition.org/tsafon/2049

DOI : 10.4000/tsafon.2049

ISSN : 2609-6420

Éditeur

Association Jean-Marie Delmaire

Édition imprimée

Date de publication : 1 septembre 2019

Pagination : 165-166

ISSN : 1149-6630

\section{Référence électronique}

Par Danielle Delmaire, «Chahut lors d'un colloque sur la Shoah en Pologne », Tsafon [En ligne], 77 |

2019, mis en ligne le 09 septembre 2019, consulté le 23 juin 2021. URL : http://

journals.openedition.org/tsafon/2049; DOI : https://doi.org/10.4000/tsafon.2049 


\section{Informations......}

\section{Disparition n'est pas oubli !}

Par Danielle Delmaire

Nous réitérons le titre donné à l'hommage rendu à Simone Veil, Marceline LoridanIvens, et Ida Grinspan (décédées en 2017-2018), dans la rubrique « Informations » de notre numéro précédent, pour nous souvenir de Joseph Peretz.

C'est avec tristesse que nous avons appris le décès Joseph Peretz au Canada. Il était le dernier survivant du Judenlager des Mazures. Il s'est éteint dans son sommeil et il venait d'avoir 98 ans.

Né à Anvers en 1921, il a pu s'évader de la gare de triage de Charleville lors du transfert vers Drancy. Il fut aidé par Léon Devingt, chef de gare de Revin, son épouse Madeleine et leurs deux filles, Geneviève et Lisette. Il leur a voué une reconnaissance durable : leurs photos étaient toujours près de lui.

Après la guerre, Joseph Peretz a émigré au Canada où il a fondé une famille et où vivent sa fille et ses petits-enfants.

Il n'a jamais oublié ses mois passés Judenlager des Mazures. Il n'a pas hésité à aider l'historien Jean-Émile Andreux pour reconstituer l'histoire du Judenlager des Mazures et pour élaborer un Mémorial de tous les déportés (Jean-Émile Andreux, « Mémorial des déportés du Judenlager des Mazures », Tsafon, $\mathrm{n}^{\circ} 3$ hors-série, octobre 2007). Il a lui-même rédigé ses mémoires: The endless wait.

\section{Chahut lors d'un colloque sur la Shoah en Pologne}

Par Danielle Delmaire

Les 21 et 22 février se déroulait, à l'EHESS (l'École des Hautes Études en Sciences Sociales) de Paris, un colloque international sur « la nouvelle école polonaise d'histoire de la Shoah », en partenariat avec la Fondation pour la Mémoire de la Shoah, le CNRS et l'Université de Strasbourg. Le but des organisateurs du colloque, Olga Byrska (EHESS), Audrey Kichelewski (Université de Strasbourg), Judith Lyon-Caen (EHESS), Jean-Charles Szurek (CNRS), Dominique Trimbur (FMS), Annette Wieviorka (CNRS), Claire Zalc (EHESS/CNRS), était de présenter au public français des travaux, récents et novateurs, sur l'histoire de la Shoah en Pologne et de diffuser les derniers échos des recherches entreprises par des historiens polonais et d'autres pays.

Avant l'ouverture de ce colloque, la direction de l'EHESS avait subi des pressions, parfois menaçantes, pour annuler le colloque. Les opposants polonais à cette manifestation scientifique ont dénoncé des discours anti-polonais, refusant de reconnaître l'implication des certains Polonais dans le massacre de juifs. Selon eux, ce 
qui s'est passé en Pologne est le fait des seuls Allemands. Durant le colloque, ils affichaient un nationalisme sourcilleux dans une expression verbale violente, interrompant les conférenciers, les accusant de nuire à la réputation de la Pologne et de falsifier l'histoire de la Shoah en Pologne.

Des chercheurs polonais, de réputation internationale, ont été conspués. Le professeur Jacek Leociak de l'Académie des sciences de Pologne a été insulté. Le professeur Jan Grabowski, de l'Université d'Ottawa, a été apostrophé par un « sale juif ». Jan Tomasz Gross, de l'université de New York et auteur du livre Les voisins. Un massacre en Pologne, 10 juillet 1941 (paru en 2001, sorti en français chez Fayard en 2002 et réédité par Les Belles Lettres en mars 2019) à propos du massacre de juifs par leurs voisins polonais à Jedwabne, a lui-même été mis à mal, tant ses travaux sont rejetés par un courant nationaliste polonais qui gagne du terrain et dont les représentants se sont manifestés bruyamment lors de ce colloque. Les perturbations verbales accompagnées de gestes réprobateurs ont empêché la bonne tenue de cette rencontre scientifique internationale.

Le directeur de l'EHESS ainsi que la ministre de tutelle se sont émus de ces incidents qui ne sont pas anodins.

Dans son numéro 60 de l'automne 2010 - hiver 2001, Tsafon publiait un dossier sur «Mille ans de vie juive en Pologne», dans lequel Edyta Gawron, de l'université Jagellonne de Cracovie, signait un article intitulé : «L'histoire des Voisins de J.T. Gross comme exemple d'incitation à un débat historique national» (p. 51-69). Elle y rendait déjà compte de la controverse que suscitait l'ouvrage de J.T. Gross, en Pologne. 